\title{
Design cerâmico e aproveitamento de resíduos sólidos: desenvolvimento de porcelana a partir das cinzas de ossos bovinos
}

Ceramics design and reuse of solid waste: producing porcelain from the ashes of bovine bones

ARAÚJO, Railde Paula Diniz

Universidade Federal do Maranhão - UFMA I raildediniz@gmail.com

SANTOS, Denilson Moreira

Universidade Estadual Paulista - UNESP I denilson.santos@ufma.br

\begin{abstract}
Resumo
O trabalho apresenta a obtenção de cerâmica tipo porcelana a partir da incorporação de cinza de ossos bovinos, por meio de calcinação e moagem dos mesmos, desenvolvimento de moldes de gesso e testes com óxidos, resultando na vitrificação de peças cerâmicas em referência à culinária maranhense. Como resultado, foram desenvolvidas petisqueiras de porcelana. Diminuindo os descartes de resíduos sólidos descartados na natureza e inserindo posteriormente este conhecimento nas comunidades ceramistas do Maranhão, buscou-se contribuir para o desenvolvimento local utilizando o design.
\end{abstract}

Palavras-chave: Design de produto. Porcelana. Ossos bovinos. Resíduos.

\section{Abstract}

This study presents the process of obtaining porcelain from the ashes of bovine bones through calcination and milling procedures. Plaster molds and testing with oxides are part of the methods applied, resulting in the vitrification of ceramic pieces. Using this process, a series of porcelain snack bowls were designed inspired by the cuisine of Maranhão - a Brazilian state. By decreasing the amount of solid waste discarded in nature and by spreading new knowledge among ceramic producers in Maranhão, we strived to contribute with the development of local communities through design.

Keywords: Product design. Porcelain. Cattle bones. Solid waste. 


\section{INTRODUC̣ÃO}

Vivemos em uma época em que existe uma grande preocupação com a sustentabilidade, sobretudo quando o assunto diz respeito ao descarte dos resíduos sólidos. Estes resíduos necessitam de um destino adequado, pois quando descartados, coletados e tratados inadequadamente, podem provocar efeitos diretos e indiretos na saúde da população e contribuem também para a degradação do meio ambiente.

O Brasil é o maior produtor de gado para o abate no mundo, gerando grande quantidade de resíduos após processamento, tais como os ossos e outros componentes. Ao utilizar os ossos bovinos na composição de porcelanas pela indústria cerâmica, é possível contribuir, portanto, para a diminuição desse resíduo, visando o aspecto ambiental, mas também para os aspectos sociais, culturais e econômicos do país.

\section{REVISÃO BIBLIOGRÁFICA}

Segundo Granziera (2009), "os resíduos são materiais e substâncias que, depois de utilizados, se não tiverem destinação adequada, podem pôr em risco as atividades que venham a ser desenvolvidas onde foram dispensados".

$\mathrm{Na}$ literatura existem estudos relacionados à porcelana de ossos e suas propriedades, tais como os autores Bragança e Bergmann (2006), Miyahara, Gouvêa e Toffoli (2006) e Lima (2006), que ressaltam a importância do material no campo da pesquisa e de sua produção.

Os resultados de Bragança e Bergmann (2006), mostraram que a porcelana de ossos apresenta maior tensão de ruptura à flexão e elevada resistência mecânica em relação às porcelanas comuns, o que possivelmente pode resultar em um produto com o valor mais elevado, porém de excelente qualidade.

Segundo Miyahara, Gouvêa e Toffoli (2006), além de compor esse tipo de porcelana, as cinzas de ossos poderiam ser utilizadas na produção de bioimplantes, substituindo materiais como a platina, que podem causar rejeição em alguns casos. Segundo o pesquisador, os ossos após lavagem e queima, transformam-se em hidroxiapatita, um mineral dotado de propriedades incluindo a biocompatibilidade.

Segundo Lima (2006), as porcelanas "apresentam menor grau de porosidade (quase não absorvem água) sendo as mais comuns obtidas a temperaturas de queima que variam entre $1200^{\circ} \mathrm{C}$ e $1400^{\circ} \mathrm{C}$ o que contribui para que o material vitrifique por completo obtendo uma aparência translúcida". 
As principais qualidades da porcelana de ossos são a alvura, a translucidez, refletividade, qualidade do vidrado e decoração, além da elevada resistência mecânica. Este conjunto de propriedades faz deste produto um dos mais atrativos e caros, distinguindo-se da louça de mesa comum pelo termo bone porcelain (BRAGANÇA; BERGMANN, 2006).

O setor de louças refinadas e de elevada qualidade, no entanto, são praticamente inexiste no Brasil, cujos produtos competem num nicho inferior de mercado. Mas um aspecto bastante relevante é o fato desta porcelana ser produzida com $50 \%$ de matéria-prima proveniente de um material reaproveitado, como os ossos bovinos calcinados que, atrelado à recente conscientização da preservação ambiental, a porcelana de ossos passou a despertar interesse de pesquisadores, o que deve impulsionar o seu desenvolvimento e sua produção. Este fato levou os autores a investigarem os principais parâmetros técnicos para a produção desta porcelana, cujos resultados foram publicados em outros trabalhos (BALLVÉ PRATES; BRAGANÇA, 2010) e aplicados no desenvolvimento de produtos por designers.

De acordo com o SEBRAE (SENAC, 1999), são três os objetivos dos designers no que diz respeito à intervenção no artesanato: promover o acesso a tecnologias adequadas ao aumento e melhoria da capacidade produtiva, utilizar a inovação como um dos fatores de diferenciação do produto artesanal e resgatar a cultura como fator de agregação de valor ao artesanato.

Portanto, a aplicação do design deve promover a qualidade dos produtos, dos territórios e dos processos de fabricação, deve apoiar a comunicação e aproximar produtores e consumidores intensificando as relações territoriais, valorizando a cultura, projetando pensando no desenvolvimento sustentável, visando o fortalecimento de micro e pequenas empresas.

\section{MATERIAIS E MÉTODOS}

\subsection{Materiais}

\subsubsection{Obtenção do pó de osso bovino}

Como etapa inicial desta pesquisa, foi realizada a obtenção de ossos bovinos. Por ser um material quase sempre descartado diretamente na natureza, foi fácil a sua obtenção, foi obtido com a seleção de ossos consumidos em ambientes domésticos. 


\subsubsection{Confecção da porcelana}

A metodologia utilizada para a confecção da porcelana a partir de ossos bovinos é a mesma utilizada para confecção de produtos cerâmicos. Existem várias técnicas utilizadas na indústria e descritas pela literatura, mas neste trabalho os produtos foram conformados por dois processos: a colagem de barbotina, por ser uma técnica muito simples e de baixo custo, sendo mais acessível e adequada para utilização em comunidades; e a técnica de produção por placas, no qual a massa é preparada e moldada no interior do molde de gesso. Ambos os processos já são utilizados pelas comunidades ceramistas locais.

\subsection{MÉTODOS DE DESIGN}

Para o desenvolvimento deste projeto, foram utilizadas as metodologias de design de Löbach (2001) e Baxter (2001), com utilização de suas técnicas e métodos de acordo com as necessidades do projeto. Os autores foram escolhidos por abordarem de forma simples, clara e objetiva as questões projetuais.

Foram utilizadas as seguintes etapas para a configuração deste projeto: Briefing (listas de requisitos), conceito do produto, geração de ideias, análise das ideias, escolha da ideia.

\subsubsection{Briefing (lista de requisitos)}

Segundo Baxter (2001, p. 228), "a especificação do projeto pode ser considerada como uma hierarquia de necessidades, que vai dos requisitos de performance (o que se exige do produto) aos requisitos de projeto (como o produto deve ser), chegando aos (critérios quantitativos)". Portanto, nesta etapa foram citados todos os elementos considerados importantes para o produto.

\subsubsection{Conceito do produto}

Para Löbach (2001, p. 156):

O conceito estético provém da palavra grega aesthesis e significa algo como percepção sensorial. Com isto se 
considera apenas um aspecto da estética. A definição mais ampla da estética considera-a como: ciência das aparências perceptíveis pelos sentidos (por exemplo a estética do objeto) e sua importância para os homens como parte de um sistema sociocultural (estética de valor)

No desenvolvimento de um projeto de Design, o conceito é primordial para melhor entendimento do projeto como um todo e para construir uma identidade com a qual o usuário venha se identificar.

\subsubsection{Geração das ideias}

Para Löbach (2001, p. 153), "gerar ideias é a produção das diversas alternativas possíveis para solucionar o problema em questão". Portanto, nessa etapa foram feitos os esboços do projeto, ou seja, os desenhos dos possíveis produtos levando sempre em consideração o conceito do produto e a lista de requisitos para se conseguir atingir as funções do produto, que correspondem às funções práticas, estéticas e simbólicas.

\subsubsection{Análise das ideias}

Nesta fase, foram analisadas todas as propostas geradas na etapa anterior, pois segundo Löbach (2001), "a avaliação de alternativas de design é importante para que, no final da fase de análise, sejam fixados os critérios de aceitação do novo produto. Só assim o designer pode escolher, dentre as alternativas de projeto, a melhor solução".

\subsubsection{Escolha da ideia}

A escolha deve ser sempre o mais apropriado para o projeto tendo as necessidades do cliente atendidas, para que haja a satisfação tanto do projetista quanto do mesmo. A escolha da ideia exige conexão com os vários critérios preestabelecidos e o conceito, levando em consideração a lista de requisitos elaborada, durante a execução do projeto. 


\subsection{Confecção dos Moldes de Gesso das Petisqueiras}

A técnica do molde de gesso de um produto cerâmico exige certo tipo de habilidade manual e isso também depende do tipo de molde a ser confeccionado. A utilização de moldes consiste em uma técnica muito utilizada pelos ceramistas em todo o território brasileiro, por ser de fácil confecção e de baixo custo.

\subsection{Preparo da Massa Cerâmica}

Para o processo de preparação da barbotina, foram realizados alguns testes anteriormente para analisar a melhor composição para o projeto. Como resultado, chegou-se à composição de $50 \%$ de pó de ossos bovinos, $25 \%$ de argila, 7,5\% de Caulim, 7,5\% de Quartzo e 10\% de Feldspato.

\subsection{Desmoldagem}

A etapa de desmoldagem é bem simples para ambas as técnicas. No processo de barbotina, o gesso absorve a água da peça, proporcionando diminuição dimensional e seu descolamento junto ao molde após algumas horas de descanso. Às vezes é necessário colocar as peças viradas para baixo para se soltarem com mais facilidade.

Já no processo da confecção de placas, a desmoldagem é mais rápida e a peça sai logo após sua conformação, possibilitando uma grande quantidade de peças produzidas em um único dia.

\subsection{Secagem}

Na secagem, as peças perdem mais água para o meio ambiente. Elas adquirem uma coloração cinza e são chamadas de "peça verde" nessa fase. As peças precisam secar naturalmente por um período que varia em relação ao tamanho e peso da peça, da temperatura ambiente e do grau de umidade do ar. Essa etapa reduz o risco de quebra quando as peças forem levadas ao forno. 


\subsection{Queima}

A queima é a etapa mais importante da fabricação dos materiais cerâmicos, na qual ocorrem reações químicas que modificam estruturalmente a cerâmica. Por isso, deve ser uma etapa planejada e bem estruturada com controle de tempo e de temperatura, com pré-estabelecimento inclusive das velocidades de aquecimento, de resfriamento, a atmosfera ambiente, o tipo de forno utilizado, etc.

\subsection{Esmaltação e Vitrificação}

A esmaltação consiste na pintura das peças com a utilização de óxidos, para posterior queima, para que as torne uma cerâmica vitrificada. Os vidrados cerâmicos geralmente contêm sílica na formação do vidro que, combinada com uma mistura de óxidos de metal como sódio, potássio e cálcio, agem como fundente e permitem ao vidrado fundir-se a uma determinada temperatura.

A alumina também é utilizada com a função de endurecer o vidrado e evitar que escorra da peça, corantes como óxido de ferro, carbonato de cobre e por vezes opacificantes como óxido de estanho ou óxido de zircônia.

\section{RESULTADOS E DISCUSSÕES}

\subsection{Obtenção do Pó de Osso Bovino}

Os ossos foram lavados, secados e levados ao forno, para serem queimados a uma temperatura de $1000^{\circ} \mathrm{C}$. Após esse processo da queima, os ossos são "moídos" em um pilão até adquirir o pó de osso, ou submetido ao processo de moagem a seco em moinho de bolas. Depois, esse pó é peneirado em uma peneira de tela 100 mesh, resultando no pó de ossos bovino pronto para ser utilizados, conforme mostra a Figura 1. 
Figura 1 - Pó de ossos bovinos.

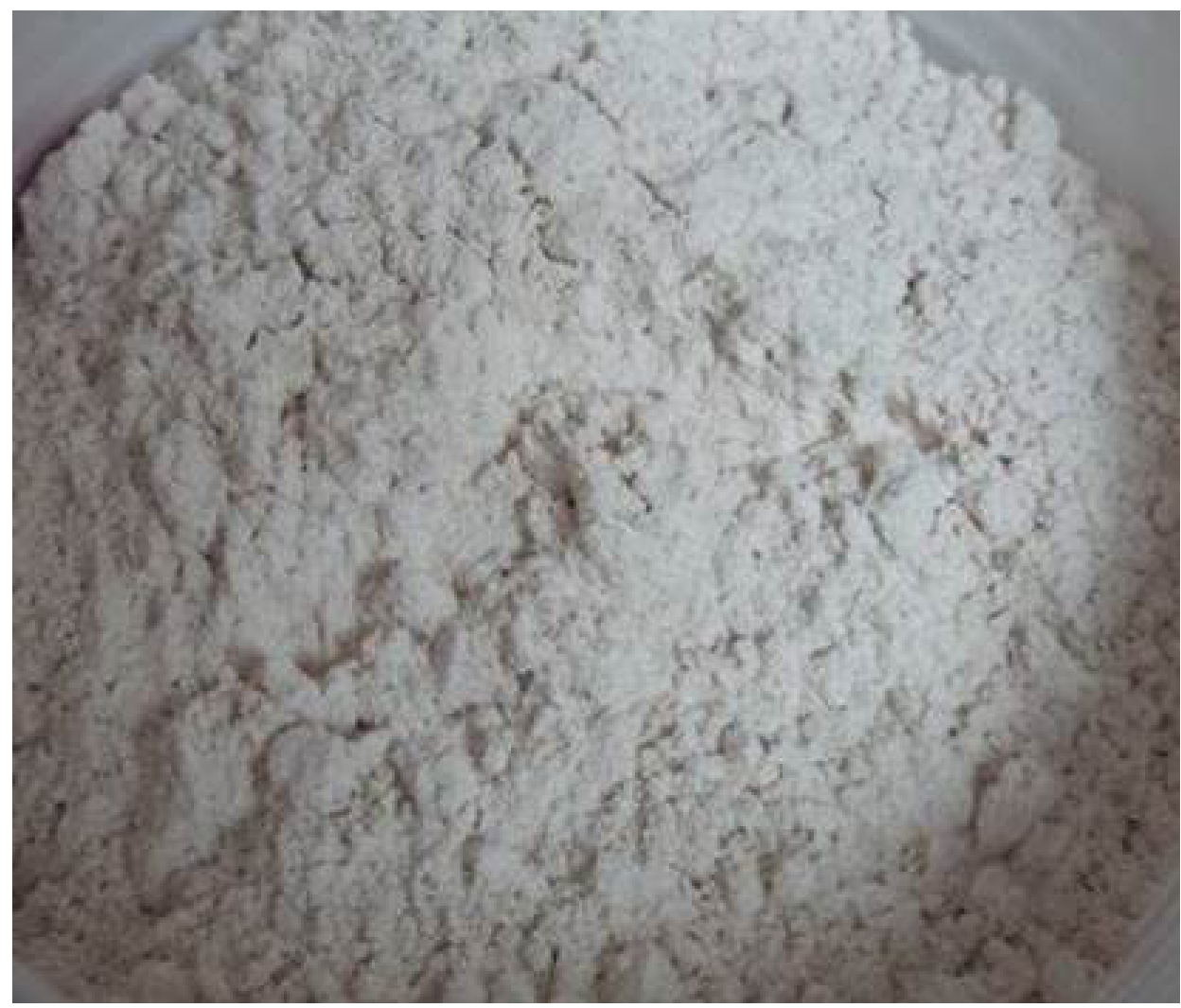

Fonte: Elaborado pelo autor, com base na pesquisa realizada.

\subsection{Briefing (Lista de Requisitos)}

Levando em consideração que as petisqueiras são um utensílio de cozinha e que devem proporcionar segurança, conforto durante o manuseio pelo usuário e principalmente proporcionar facilidade de higienização uma vez que se trata de um produto que vai estar em contato com produtos alimentícios, foi elaborada uma lista de requisitos, com itens a serem atendidos pelo projeto. Segue abaixo a lista de requisitos:

- $\quad$ As petisqueiras não devem conter arestas e nem pontas, pois podem prejudicar na retirada da peça do molde de gesso, como também podem causar algum acidente com o usuário;

- Devem proporcionar a higienização, ou seja, devem ser fáceis de lavar;

- Devem ter uma dimensão razoável para comportar uma certa porção de alimentos;

- Devem proporcionar conforto para o usuário durante seu manuseio;

- Devem proporcionar vários conjuntos possíveis de arranjos, gerando liberdade ao usuário para montar as petisqueiras de várias maneiras. 


\subsection{Conceito do Produto}

O conceito para o conjunto de petisqueiras foi baseado na culinária maranhense, especificamente nos frutos do mar. Devido à localização geográfica do Estado e, em especial a capital São Luís, o Estado é contemplado por uma extensa faixa litorânea, com grande visitação, que gera como consequência o consumo de uma grande variedade de frutos do mar.

Quanto ao produto, a petisqueira foi escolhida por se tratar de um objeto passível de ser desenvolvido em cerâmica, com facilidade de confecção e produção, e por ser muito utilizado para servir pequenas porções às pessoas em restaurantes, podendo agir como reforçador de identidade. Este projeto foi pensado para deixar o produto com um aspecto dinâmico, lúdico e simbólico. Figura 02 - Conceito frutos do mar.

Figura 2 - (A) caranguejos; (B) Conchas; (C) Camarões.

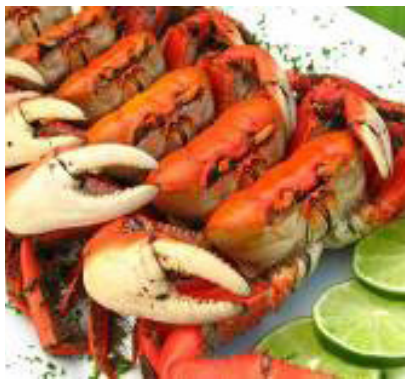

(A)

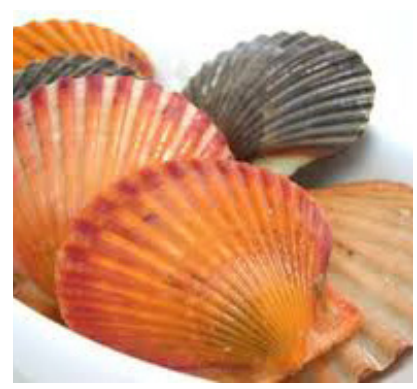

(B)

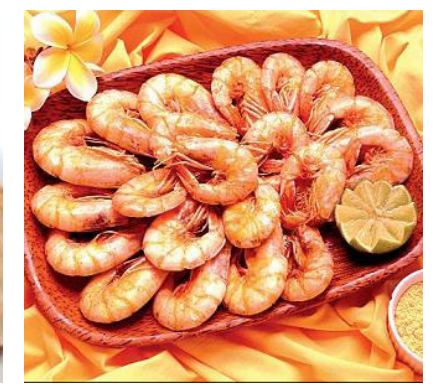

(C)

Fonte: Google (2015).

\subsection{Geração das Ideias}

Levando em consideração o conceito do produto e a lista de requisitos, foram geradas as seguintes ideias para as petisqueiras.

\subsection{Análise das Ideias}

Nessa etapa foram avaliadas as ideias apresentadas, considerando os critérios e a lista de requisitos que o produto deveria conter. Para isso, foi desenvolvida a Tabela 1, referente à análise das ideias. 
Tabela 1 - Análise das ideias.
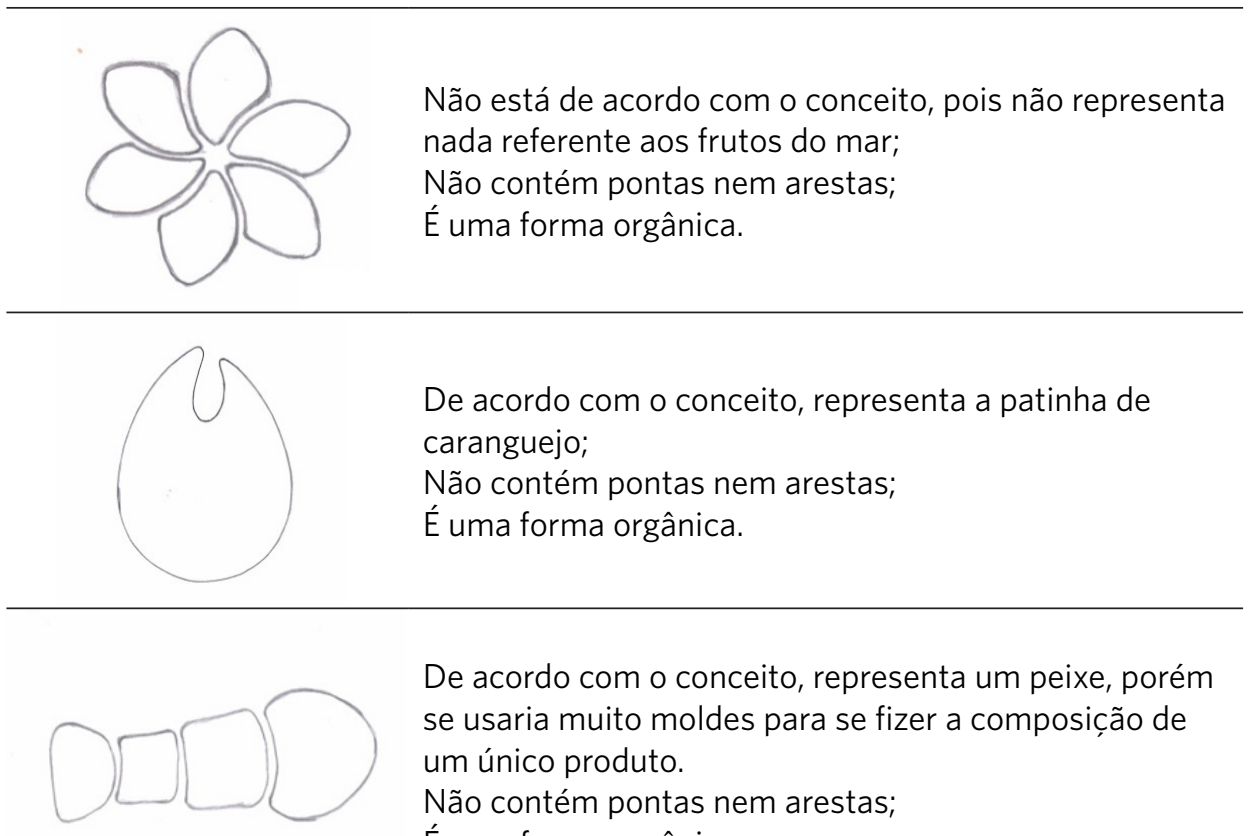

De acordo com o conceito, representa um peixe, porém se usaria muito moldes para se fizer a composição de um único produto.

Não contém pontas nem arestas;

É uma forma orgânica.

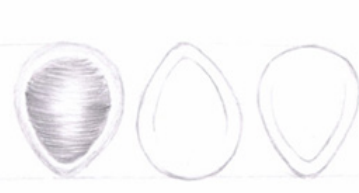

De acordo com o conceito, representa uma espécie de concha, porém preferiu-se outro modelo por ser mais atrativo e simbólico;

Não contém pontas nem arestas;

É uma forma orgânica.

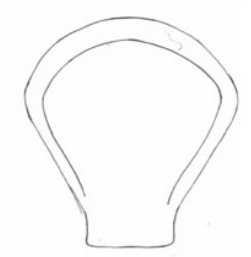

De acordo com o conceito, representa a concha do mar; Não contém pontas nem arestas;

É uma forma orgânica.

Fonte: Elaborado pelo autor, com base na pesquisa realizada.

\subsection{Escolha da Ideia}

As ideias escolhidas para o desenvolvimento do produto foram as petisqueiras com formato de pata de caranguejo e em forma de conchas, pois apresentaram uma uma maior similaridade com o que foi citado na lista de requisitos e com o conceito. 
Figura 3 - Ideias escolhidas.
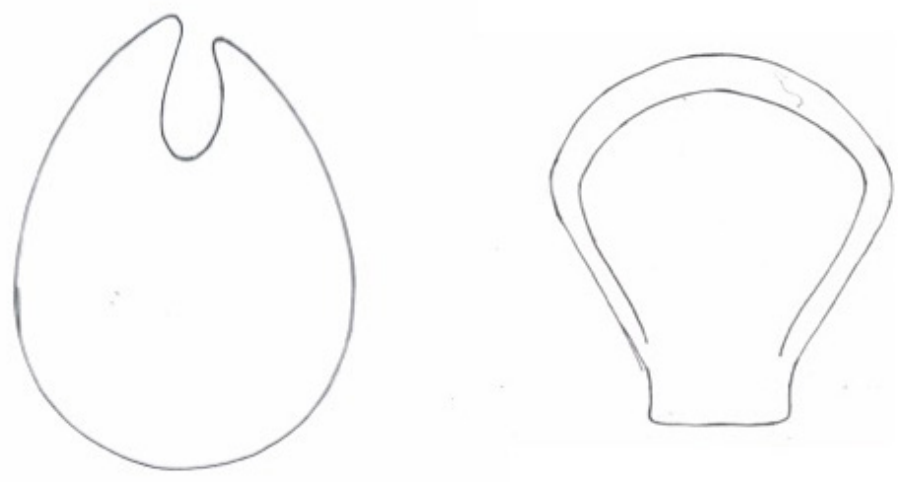

Fonte: Elaborado pelo autor, com base na pesquisa realizada.

\subsection{Composição da Massa Cerâmica Selecionada}

A composição referente ao projeto de porcelana de ossos é de $50 \%$ de pó de ossos bovinos, 25\% de argila (na cor branca e proveniente do município de Mirinzal do Estado do Maranhão), 7,5\% de Caulim, 7,5\% de Quartzo e 10\% de Feldspato.

O produto foi conformado de duas maneiras, pelo processo de colagem de barbotina e por prensagem. Para isso, foi misturada aproximadamente $700 \mathrm{~g}$ de matéria-prima, nas porcentagens acima citadas. A quantidade de água utilizada foi de acordo com a necessidade do tipo de processamento. Para a colagem de barbotina, a água acrescentada foi aproximadamente de $50 \%$, suficiente para a mistura adquirir aspecto fluido ao qual chamamos de barbotina. Já para a prensagem, a adição não passou de 15\%.

Esta composição utilizada em referência a estudos anteriores realizados com a análise de propriedades tecnológicas de corpos de prova confeccionados por prensagem. Tais propriedades foram Retração Linear e Absorção de Água, cujas médias foram $8,8 \%$ e $7,85 \%$ respectivamente, valores estes que se encontram muito próximos dos valores obtidos para a porcelana tradicional (BRAGANÇA; BERGMANN, 2006).

Sabe-se que diferentes processos de conformação podem gerar resultados distintos quanto às propriedades tecnológicas de um mesmo material, contudo estes resultados semelhantes podem indicar uma possível aplicação do material também em outras formas de processamento. 


\subsection{Resultado da Colagem de Barbotina}

No processo da colagem de barbotina, a solução da composição é colocada no interior do molde de gesso por alguns minutos para que a superfície absorva a água e as paredes da peça comecem a ser formadas. No processo, este procedimento é realizado várias vezes até que a parede do produto possua a espessura desejável de acordo com o projeto. Vale ressaltar que o formato do molde do projeto é muito orgânico, por isso foi necessário o seu constante manuseio para que as paredes ficassem uniformes.

Figura 4 - Molde sendo manuseado para a formação de paredes uniformes.

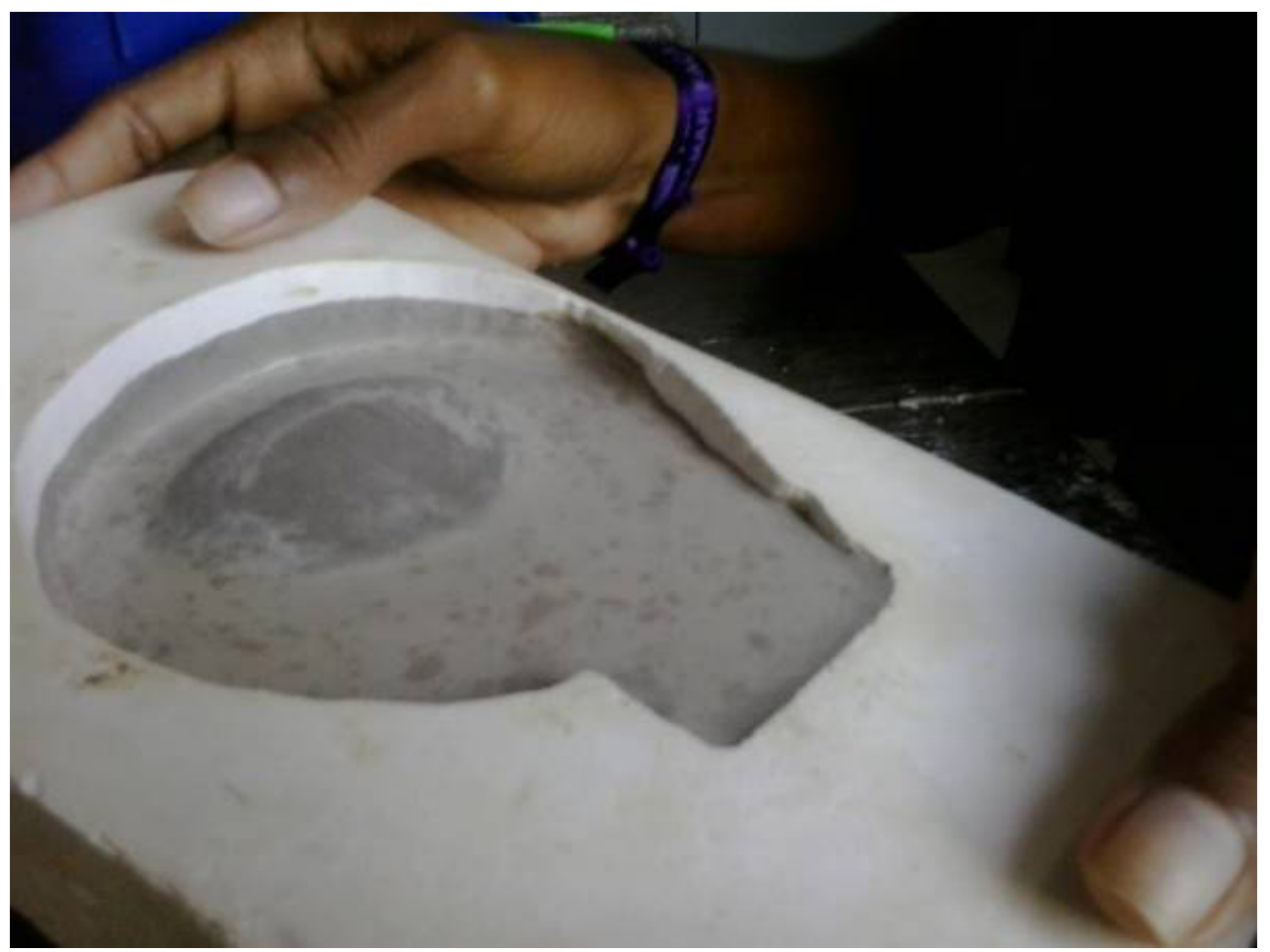

Fonte: Elaborado pelo autor, com base na pesquisa realizada.

\subsection{Confecção de Placas}

Primeiramente, é realizada a pesagem das matérias-primas da composição na balança, na qual a água vai sendo borrifada até que se alcance uma massa consistente que solte das mãos. Inicia-se, então, um processo de eliminação de impurezas e de homogeneização, para retirada as chamadas "bolhas de ar" do barro/da argila, que é fundamental para evitar defeitos ou quebras durante a etapa de queima.

Na confecção de produtos por placas, utiliza-se pouca água em relação à colagem de barbotina, depois é só moldar a massa no molde e retirar com outro pedaço de massa. 
Figura 5 - Massa sendo modelada no interior do molde.

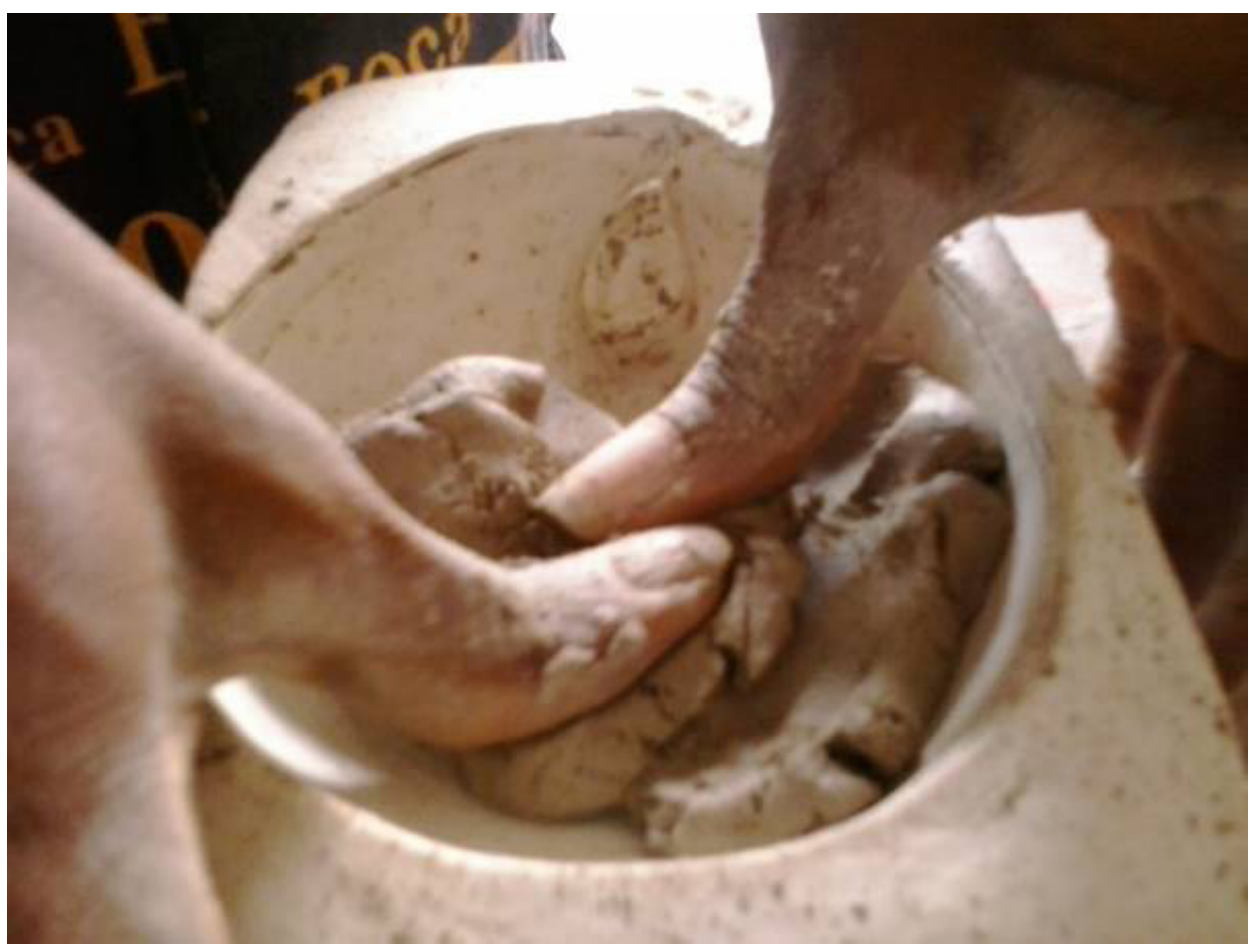

Fonte: Elaborado pelo autor, com base na pesquisa realizada.

\subsection{Desmoldagem}

A desmoldagem do processo de confecção de placas permite o descolamento da peça do interior do molde após algumas horas, permitindo a possibilidade de produção de várias peças em um mesmo dia. Quanto ao processo da colagem da barbotina a desmoldagem da peça pode demorar algumas horas, ou até um dia para sair do molde, pois as paredes do molde absorvem a água presente na barbotina, até a peça soltar-se do molde.

Figura 6 - Desmoldagem da peça.

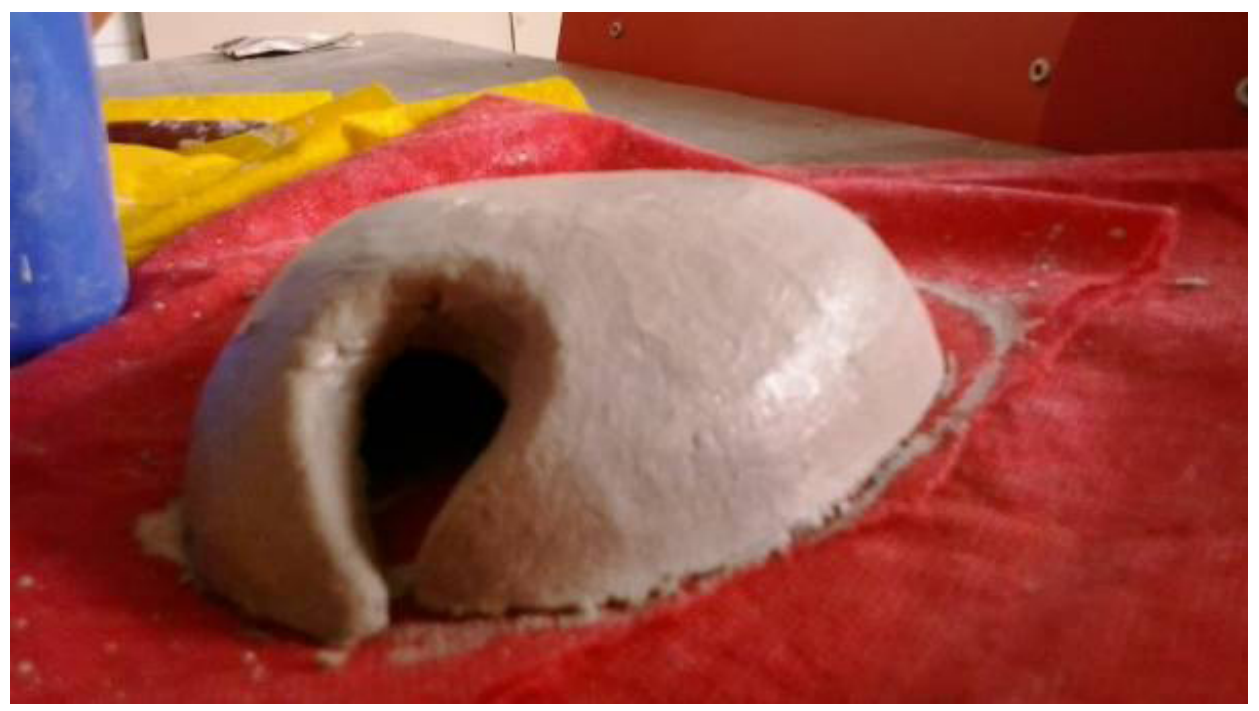

Fonte: Elaborado pelo autor, com base na pesquisa realizada. 


\subsection{Secagem}

A secagem torna-se uma etapa importante ao possibilitar a diminuição do empenamento das peças quando queimadas, por isso foi realizada durante 24 horas no ambiente.

Vale salientar que as peças também podem secar em estufas durante 24 horas a $60^{\circ} \mathrm{C}$. Neste momento, elas já perderam um pouco de água para o meio ambiente, pois necessitam de um tempo de secagem ao ar livre uma vez que não podem ir diretamente para as estufas, já que nas estufas a secagem é mais rápida e pode vir a causar empenamento.

Depois da etapa da secagem, as peças recebem um acabamento superficial por meio do lixamento para a retirada de imperfeições. Para isso, é importante a graduação na utilização das lixas, começando sempre de uma com numeração mais baixa para uma mais alta, pois quanto mais fina, melhor se torna o acabamento. Nessa etapa as peças são mais frágeis, é importante observar que são peças com formatos orgânicos que exigem muito cuidado no manuseio, pois estas ainda não foram queimadas, em virtude disso no projeto foram utilizadas lixas 220 .

Figura 7 - Peças secando naturalmente.

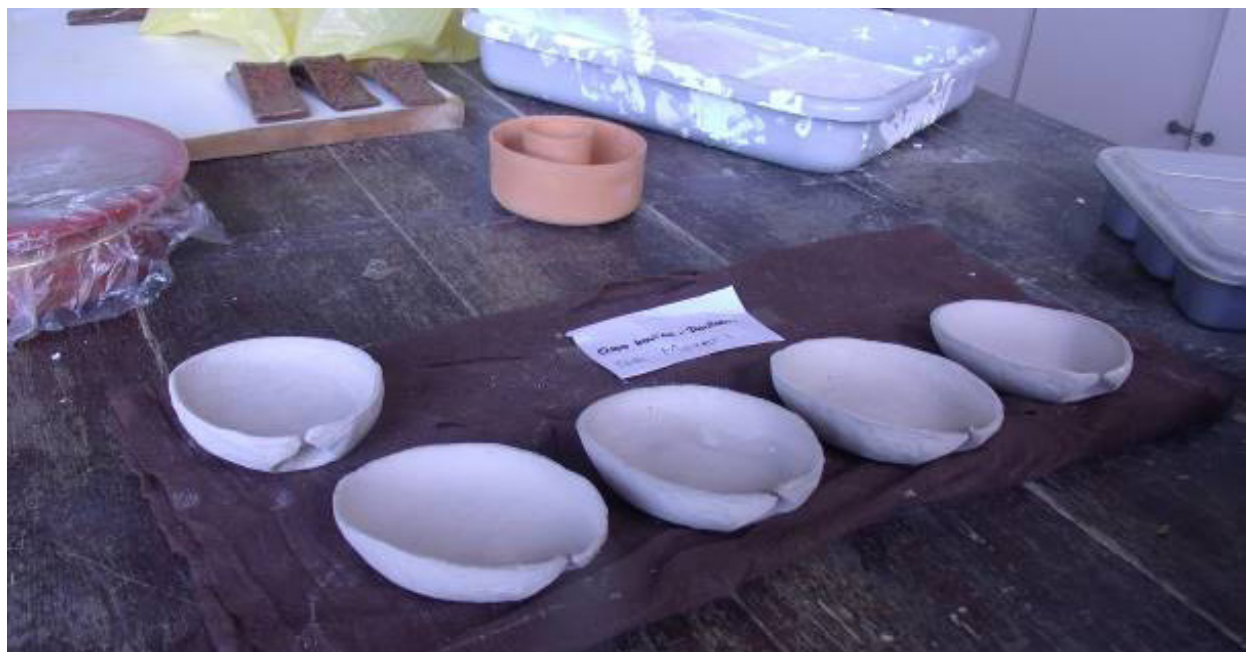

Fonte: Elaborado pelo autor, com base na pesquisa realizada.

\subsection{Queima}

As peças após lixadas, foram levadas ao forno para a queima. Conforme os resultados dos experimentos, determinou-se que a temperatura mais adequada para a queima seria de $1200{ }^{\circ} \mathrm{C}$, para evitar problemas com a vitrificação. 
Figura 8 - Peças após queima.

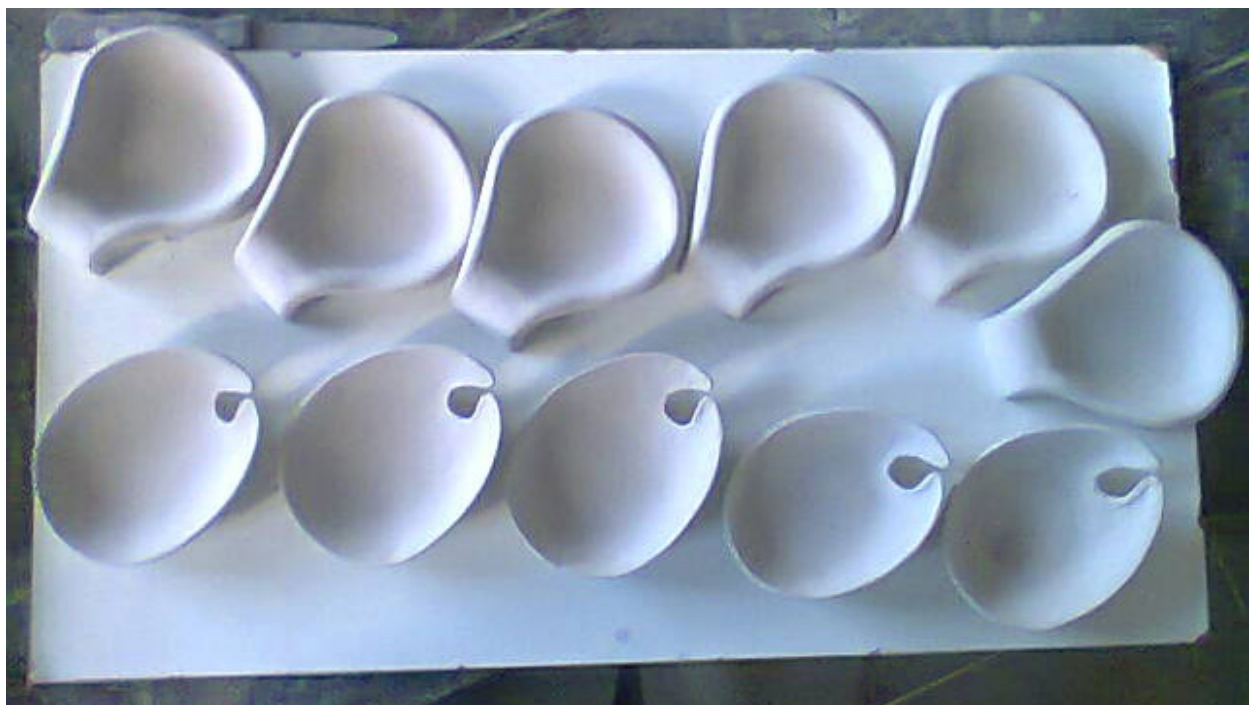

Fonte: Elaborado pelo autor, com base na pesquisa realizada.

\subsection{Esmaltação e Vitrificação.}

Primeiramente foram queimadas uma peça e alguns pedaços para testes com variações de óxidos. Os óxidos utilizados para testes foram: óxido de tonalidade branca, Preto Ébano, de tonalidade amarela, no qual foram queimados na mesma temperatura de $980^{\circ} \mathrm{C}$.

Após análise dos resultados dos testes, foram escolhidos para a vitrificação das peças os seguintes óxidos: óxido de tonalidade branca, preto e amarela, por apresentarem uma boa cobertura e esteticamente serem mais apropriados ao projeto. Foi utilizada a pintura branca por ser a mais usada nas porcelanas, porém também utilizamos outras cores como o preto e o amarelo para melhores resultados.

A peça amarela adquiriu um aspecto rústico deixando-a mais rica, já a peça preta ficou com aspecto mais sofisticado. Acredita-se que todas as peças poderiam ser bem aceitas no mercado de porcelanas.

Figura 9 - Peças vitrificadas.

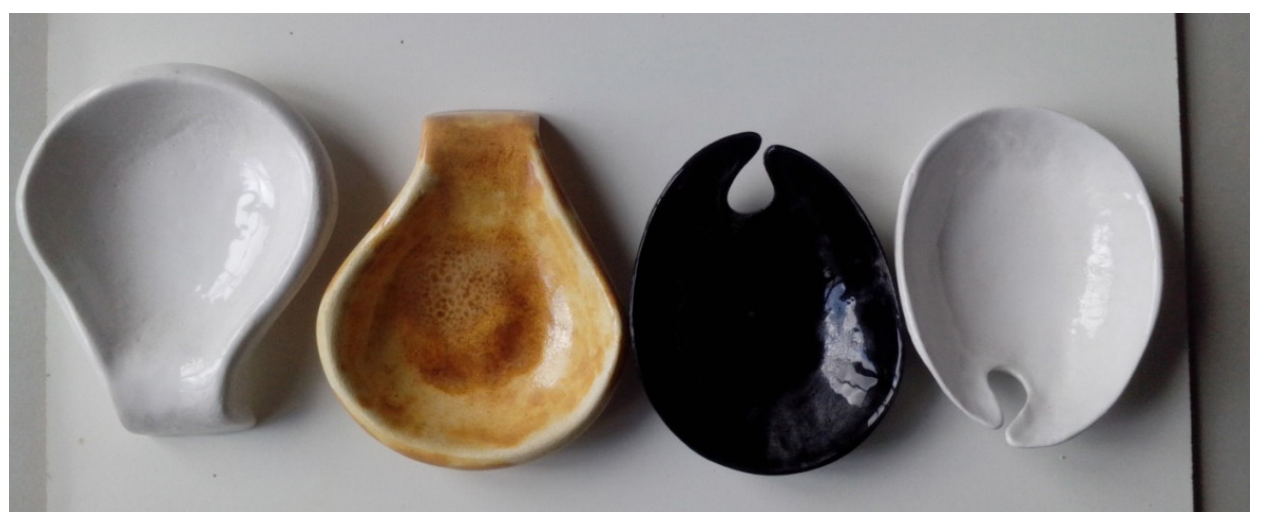

Fonte: Elaborado pelo autor, com base na pesquisa realizada.

Projética, Londrina, v.9, n.2, p. 9-24, Jul./Dez. 2018 


\section{CONCLUSÃo}

Concluiu-se que os resultados obtidos neste projeto atingiram as expectativas esperadas e que a composição desenvolvida se mostrou apropriada para fabricação das peças de porcelana. As peças apresentaram excelente qualidade, sendo o processo de confecção por placas mais indicado. Dessa forma, confirmou-se ser possível a adição dos ossos bovinos à mistura cerâmica para a fabricação de porcelana, o que possibilitaria a longo prazo a diminuição de uma parcela dos impactos causados por estes resíduos sólidos que seriam descartados na natureza e ainda contribuiriam para o desenvolvimento social, cultural e econômico das comunidades ceramistas do Maranhão. Estas consequências possibilitariam a abertura de novos mercados para essa área, praticamente inexistentes no Brasil.

\section{REFERÊNCIAS}

BALLVÉ PRATES, Mário; BRAGANÇA, Saulo Roca. Novos fundentes para produção da porcelana de ossos. Revista Cerâmica, São Paulo, v. 56, p. 57-65, 2010.

BAXTER, Mike. Projeto de produto: guia prático para os novos produtos. 2. ed. São Paulo: E. Blücher, 2001.

BRAGANÇA, Saulo Roca; BERGMANN, Carlos Perez. Produção de porcelana de ossos e caracterização de suas propriedades técnicas. Revista Cerâmica, São Paulo, v. 52, n. 322, p. 205-212, abr./jun. 2006.

GRANZIERA, Maria Luiza Machado. Direito ambiental. São Paulo: Atlas, 2009. LIMA, Marco Antônio Magalhães. Introdução aos materiais e processos para designers. Rio de Janeiro: Ciência Moderna, 2006.

LÖBACH, Bernard. Design industrial: bases para a configuração dos produtos industriais. São Paulo. E. Blücher, 2001.

MIYAHARA, Ricardo Yoshimitsu; GOUVÊA, Douglas; TOFFOLI, Samuel Márcio. Propriedades cerâmicas de porcelana de ossos. In: CONGRESSO BRASILEIRO DE ENGENHARIA E CIÊNCIA DOS MATERIAIS, 17., 2006, Foz do Iguaçu, PR. Anais... São Paulo: IPEN, 2006. 1 CD-ROM.

SENAC. Oficinas: cerâmica. Rio de Janeiro: Senac Nacional, 1999. 